\title{
Communicate Using the Numbers 1, 2, 3, and More
}

\section{LEVERAGING} EXPECTATIONS FOR BETTER

142 he human brain reacts differently to lists of different lengths. When you align what you say with what the human brain expects, you communicate more effectively. In this column l'll explain how to leverage the way the brain reacts to various quantities to make your speaking and writing more effective.

People often use lists of various sizes when communicating. I might have 2 reasons for supporting the new company strategy. I might tell you my 3 favorite programming languages. I might make a presentation that describes 4 new features. There is 1 vegetable that I like more than any other.

The length of the list affects how the audience interprets what is being said. Not aligning with what the human brain expects is like swimming upstream. Given the choice, why would anyone do that?

The remainder of this column focuses on 3 things:

$\Rightarrow$ Part A: Lists of size 2, 3, and 4 or more

$\Rightarrow$ Part B: Lists of size 1

$\Rightarrow$ Part C: Giving your audience a mental roadmap

PART A: LISTS OF SIZE 2, 3, AND 4 OR MORE

As I mentioned earlier, people often use lists of various sizes when speaking and writing: 
$\Rightarrow$ I'm going to discuss 2 carmakers: Toyota and GM.

$\Rightarrow$ My 3 favorite bands are: the Beatles, the Rolling Stones, and Led Zeppelin.

$\Rightarrow$ I ate 9 types of fruit last week: apples, oranges, bananas, grapes, pineapples, cherries, watermelons, blueberries, and pomegranates.

The length of the list affects how the audience interprets what is being said.

Lists of 2 encourage comparison. When I tell you that I'm going to talk about 2 carmakers, your brain naturally starts comparing them. One is Japanese, the other is not. One is doing financially better than the other, and so on.

Your brain can't help but compare 2 items. If you want to encourage your audience to compare and contrast, present a list of 2 items. If you want to discourage comparison, add a third item as a decoy.

Lists of 3 are interesting for a different reason. Typically, people can hold 3 things in their minds at once. If you are going to talk about many things but it is important that the audience hold 3 specific items in their heads as you discuss them, make sure your list is 3 or fewer.

Suppose l'm going to talk about rock bands for an hour. During that time, I'm going to be switching the discussion from one band to the next. I need the audience to hold onto the names of these bands or they will get confused. Therefore, I better not talk about more than 3 bands. More than that is too much cognitive load. The audience will get confused, bored, or worse.

What about lists of 4 or more? These are difficult for the human brain to remember. In fact, if I told you that last week I ate 9 types of fruit: apples, oranges, bananas, 
grapes, pineapples, cherries, watermelons, blueberries, and pomegranates... it is pretty reasonable to assume that you won't remember the entire list.

What you will remember, however, is that the list is very long. If my intention is to convince the audience that I like a lot of variety, listing many fruits will drive that point home. Next week you won't remember specifically what I liked, but you'll remember I liked many different types of fruit.

If I want the audience to remember exactly which fruits I like, I better make it a shorter list.

What if I really, really, really want people to remember a list longer than 3 ? The best you can do is to group the items into 3 categories. People will remember the categories, not the individual items.

\section{PART B: LISTS OF SIZE 1}

If you really want people to remember something, the best approach is to talk about that 1 thing, and nothing else. Any added information is a distraction. Murphy's law will result in people remembering the distraction, not what you wanted them to remember.

While I mentioned 9 types of fruit earlier, the vegetable I would like to tell you about is a list of size 1: broccoli.

I want you to remember that I like broccoli. Therefore, I'm going to mention only 1 vegetable: broccoli.

As an engineer, I may feel compelled to let you know that I like other vegetables too, that I'm not exclusive to broccoli. I'm not going to mention those other vegetables, however. That would be a distraction.

I want the list to have 1 item on it, and I'm going to repeat 
f you want the audience to remember something, don't distract them with things you don't want them to remember. that 1-item list a lot.

I like broccoli. That's what I want you to remember. In the past month l've had broccoli 6 different ways: raw, steamed, sautéed, roasted, blanched, and in a garlic sauce. I love broccoli. I really love broccoli.

Next week when I ask you about this you will remember that I like broccoli because I had the self-control not to mention any other vegetables. I'm not going to tell you about other vegetables that I like such as... No, no, no. Not gonna do it.

As an interesting aside: When I was younger, I didn't like broccoli. In March 1990, however, it became public that President George Bush disliked the vegetable, ${ }^{1}$ and that inspired me to give it another try. It turns out, I liked it.

Getting people to remember something is like getting children to eat their vegetables. As Josh Lymon reminds us, "It helps if there's nothing else on their plates." 2 If you want the audience to remember something, don't distract them with things you don't want them to remember.

PART C: GIVING YOUR AUDIENCE A MENTAL ROADMAP The third and final piece of advice when communicating with numbers is to tell the audience the quantity ahead of time. Don't make them count.

In fact, you should reveal the count, then list the items, then discuss each item. Don't make the audience wait for the count or the individual items. Surprise endings are good for mystery novels but not in speaking or writing.

By doing this, you give your audience a mental roadmap of what is to come. As you present the full details, people mentally check off the items and see the progress. 
Because you gave them the count, they are prepared to react in 1 of 3 ways: compare, hold in their head, or memorize.

Begin by saying, "I'm going to tell you about 3 rock bands: the Beatles, the Rolling Stones, and Led Zeppelin," then talk about each band in the order you listed them, and conclude by telling your audience that these were your thoughts about the Beatles, the Rolling Stones, and Led Zeppelin.

This is what your grade-school teachers meant when they taught you, "Tell them what you are going to say, then say it, then tell them what you told them." When my teachers told me this, I thought it was some boring old formula, but I didn't understand the cognitive importance. It took me years to realize that by following this rule, you are creating a mental roadmap for your audience, filling in the details, then reminding them what you want them to remember.

I find this particularly useful during long presentations for 2 reasons: It fortifies the roadmap, and it helps wake up bored people in the audience.

If l've painted the roadmap at the start, as I introduce each item people can check off the previous item in their heads and mentally prepare themselves for the next item. I pause for dramatic effect, and use a slide that looks like a chapter title page. This is called bookending your topics. The pause gives people a moment to catch up with what you were saying. Call it the palate cleanser of presentations.

The pause also has the effect of waking up the bored members of the audience. (Not that you or I have ever given a boring presentation, but this bit of advice might 
help your colleagues and friends.]

Consider people in the audience who are bored with a speaker's presentation. Once they are bored, they have checked out and aren't listening. A pause will startle them and grab their attention. Maybe they're bored by the speaker's discussion of the Beatles, but they notice the pause and hear the speaker say, "Now that we've learned about the Beatles, let's talk about Led Zeppelin." Now

\section{Related articles}

$\Rightarrow$ Time Protection in Operating Systems and Speaker Legitimacy Detection Operating system-based protection from timing-based side-channel attacks; implications of voice-imitation software Adrian Colyer

https://queue.acm.org/detail.cfm?id=3344779

$\Rightarrow$ A Conversation with Steve Furber

The designer of the ARM chip shares lessons on energy-efficient computing. https://queue.acm.org/detail.cfm?id=1716385 $\Rightarrow$ The Importance of a Great Finish You have to finish strong, every time. Kate Matsudaira https://queue.acm.org/detail.cfm?id=3293457 alert, they give the speaker a second chance and start paying attention again.

For these reasons, I often structure my talks and papers as a "Top 5" or "Top 10" list. This gives the audience a mental roadmap, it creates periodic opportunities to wake up bored people, and it helps everyone gauge how much progress I've made through the list. Instead of wondering, "Oh God, how much longer is this stupid talk going to be?", they are thinking, "OK, this is point number 3 ; maybe number 4 will be more interesting." Or "He's on the third point, but he has used 80 percent of his time; this

is going to be a disaster." Or maybe they're thinking, "If this is point number 9 , I can leave now and be first in line for the conference dinner." 


\section{CONCLUSION}

These tricks really work. That's why I told you I ate 9 types of fruit before I started naming each one. I wanted to prepare your brain to hear a long list. If you weren't prepared, your brain would freak out and worry that I would never stop listing names of fruit.

That's why I told you I had 1 favorite vegetable, broccoli, and never mentioned any other vegetable.

That's why I told you this column has 3 parts. Because now you know that it is done.

\section{Postscript}

Technically, this article made 6 major points, but because I grouped them and presented them as 3, you were more likely to hold them in your head and follow along. By including this point in a postscript, l've extended the total to 7 points. By going against the rules, l've created a contrast that makes this last point stand out. Only break these rules once per talk, and do it with purpose.

\section{References}

1. Dowd, M. 1990. 'I'm President,' so no more broccoli! New York Times (March 23, A14); https:Ilwww.nytimes. com/1990/03/23/usli-m-president-so-no-more-broccoli. html.

2. Manchester: Part II. 2001. The West Wing. Season 3, episode 3 (aired October 17).

Thomas A. Limoncelli is the SRE manager at Stack Overflow Inc. in New York City. His books include The Practice of System and Network Administration (http:// 
the-sysadmin-book.com], The Practice of Cloud System Administration (http://the-cloud-book.com), and Time Management for System Administrators (http://shop. oreilly.com/product/9780596007836.do]. He blogs at EverythingSysadmin.com and tweets at @YesThatTom. He holds a B.A. in computer science from Drew University.

Copyright $(2020$ held by ownerlauthor. Publication rights licensed to ACM. 